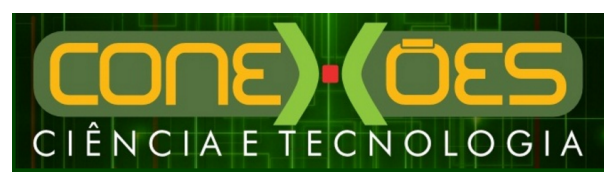

\title{
NONI (Morinda citrifolia Linn.): DETERMINAÇÃO FITOQUÍMICA E POTENCIAL ANTIOXIDANTE PELO MÉTODO DPPH
}

\author{
Leonardo Sobreira Rodrigues ${ }^{1}$, Ana Raquel Araújo da Silva ${ }^{2}$, \\ Ana AngÉlica Mathias MaCÊDO ${ }^{3}$ \\ ${ }^{1}$ Instituto Federal de Educação, Ciência e Tecnologia do Ceará (IFCE) \\ Campus de Quixadá \\ ${ }^{2}$ Universidade Estadual do Ceará \\ ${ }^{3}$ Instituto Federal de Educação, Ciência e Tecnologia do Maranhão, \\ Campus Imperatriz \\ <leorodrigues4@hotmail.com><anaraquelaraujosilva@yahoo.com.br> \\ <anaangellica@yahoo.com.br>
}

DOI: $10.21439 /$ conexoes.v11i4.921

\begin{abstract}
Resumo. As plantas medicinais vêm acompanhando a humanidade desde a sua existência, sendo utilizadas como: remédios, rituais, tinturas, dentre outras. Cientistas de todo o mundo estudam o efeito medicinal de diversas plantas. A planta Morinda citrifolia Linn., conhecida popularmente como noni, apresenta na medicina empírica diversas capacidades farmacológicas a fim de curar enfermos. Esta pesquisa busca identificar metabólitos secundários bioativos presentes na folha e fruto do noni, e avaliar apenas o potencial antioxidante da folha. Os materiais vegetais, folhas e frutos foram coletados no horto de plantas medicinais do IFCE - Campus Quixadá. Fez-se extração etanólica (75\%), testes fitoquímicos da folha e do fruto e somente determinação antioxidante pelo método DPPH da folha. $\mathrm{O}$ fruto apresentou resultado positivo para catequinas, flavonas, flavonóis, leucoantocianidinas, saponinas, taninos flobabênicos e xantonas, já a folha apresentou resultado positivo para flavonas, flavonóis, saponinas, taninos flobabênicos, xantonas mas também demonstrou eficiente capacidade antioxidante possuindo $\mathrm{EC}_{50}$ igual a 4,27 $\pm 0,004 \mathrm{~g} / \mathrm{L}$ e linearidade de $99,54 \%$. Sugere-se que a folha e o fruto sejam eficazes para o desenvolvimento de setores alimentícios e farmacêuticos, pois apresentam constituintes fitoquímicos e antioxidantes capazes de combater e prevenir enfermidades.
\end{abstract}

Palavras-chaves: Antioxidante. Metabólitos Secundários. Morinda citrifolia Linn. Plantas Medicinais.

\begin{abstract}
Medicinal plants have accompanied humanity since its existence, being used as medicines, rituals, dyes, among others. Scientists around the world are studying the effect of various medicinal plants. The Morinda citrifolia Linn. plant, commonly known as noni presents empirical medicine several pharmacological capabilities in order to heal the sick. This research aims to identify bioactive secondary metabolites present in the leaf and fruit of noni, and evaluate only the antioxidant potential of the sheet. The plant material, leaves and fruits were collected in the garden of medicinal plants IFCE Campus Quixadá. There was ethanol extraction (75\%), phytochemicals tests of leaf and fruit and only determination antioxidant of sheet, by the method DPPH. The fruit has a positive result for catechins, flavones, flavonoids, leucoanthocyanidins, saponins, tannins and xanthones, since the sheet was positive for flavones, flavonols, saponins, tannins, xanthones but also demonstrated efficient antioxidant capacity having $\mathrm{EC}_{50}$ equal to $4,27 \pm 0,004 \mathrm{~g} / \mathrm{L}$ and linearity $99.54 \%$. It is suggested that leaf and fruit are effective for the development of food and pharmaceutical sectors, as they present phytochemical constituents and antioxidants can combat and prevent diseases.
\end{abstract}

Keywords: Antioxidant. Secondary Metabolites. Morinda Citrifolia Linn. Medicinal Plants. 


\section{INTRODUÇÃO}

As plantas medicinais vêm acompanhando a humanidade desde a sua existência, e com o passar do tempo, o conhecimento empírico foi sendo difundido em diferentes culturas. $\mathrm{O}$ uso de remédios oriundos de plantas para os cuidados da saúde tem sido atribuído as suas propriedades medicinais (ALMASSY JÚNIOR et al. 2005).

A medicina tradicional, que utiliza plantas medicinais, possui grande importância em países que se encontram em desenvolvimento, pois elas são fonte de tratamento para doenças menores, por conta do alto custo de medicamentos para o cuidado da saúde pessoal. Desta forma, pesquisas relacionadas a novos medicamentos fitoterápicos têm se intensificado a cada ano (WAGNER; HIKINO; FARNSWORTH, 2012).

A fitoquímica estuda e identifica princípios ativos ou metabólitos secundários (MS) presentes nas plantas. Os MS são responsáveis por desempenhar papel fundamental na estrutura da planta, como por exemplo: combater a herbivoria e propiciar a atração de animais polinizadores, isto devido aos seus constituintes químicos que favorecem a atividade biológica então, podem ser isolados para o desenvolvimento de fitofármacos, pois desempenham importante função (AVELLO; CISTERNAS, 2010)

Os princípios ativos possuem como grupo principal as classes: terpenóides (Figura 1A), alcalóides (Figura 1B) e flavonóides (Figura 1C) e podem ser encontrados nas diferentes partes da planta (raiz, semente, seiva, caule, folha, flor e fruto). Os terpenóides são compostos de cadeia aberta ou cíclica derivadas de unidades do isopreno, encontrados em óleos essenciais, resinas e ceras das plantas, onde essa estrutura normalmente apresenta características ligadas à aromaticidade e à pigmentação das plantas medicinais (BOHLMANN; KEELING 2008).

A estrutura molecular do D-limoneno é um exemplo de terpenóide, que é encontrado tanto na casca como na polpa da laranja. Os alcalóides são compostos que apresentam cadeia cíclica e possuem o átomo de nitrogênio em estado de oxidação negativo (PELLETIER, 1999), a maioria apresenta caráter alcalino, possui papel fundamental no controle de crescimento, agente de desintoxicação e proteção contra raios UV na planta (WALLER. 2012).

Um exemplo de alcalóide é a molécula de cafeína presente no grão de café. Os flavonóides são compostos do grupo dos polifenóis e proporcionam a planta algumas funções, como por exemplo, de defesa, ação antifúngica, antibacteriana, e atrai agentes polinizado- res, além de proporcionar a planta uma variedade de pigmentação (HARBORNE, 2013). No organismo humano, atua principalmente como agente antioxidante evitando assim os radicais livres (SULTANA; ANWAR. 2008). A molécula de Quercetina é classificada como flavonóide e pode ser encontrada em diversas frutas e legumes, tais como: cebola e maçã.

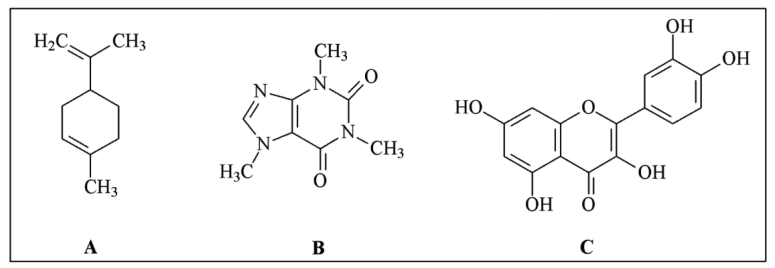

Figura 1: Estrutura química: (A) terpenóide(D-Limoneno), (B) alcalóide (Cafeína), (C) flavonóide (Quercetina).

Radicais livres são moléculas altamente instáveis, pois possuem deficiência de elétrons em sua estrutura, pelo processo de oxi-redução. Formam-se, naturalmente no organismo ou são ocasionadas por agentes externos. Para obter a estabilidade, as moléculas capturam elétrons de outras moléculas, produzindo uma reação em cadeia, denominado estresse oxidativo (JONES , 2008). O estresse oxidativo provém do desequilíbrio de moléculas oxidante (s) e antioxidante (s), sendo as moléculas oxidantes em maior quantidade. O desequilíbrio pode ocasionar diversas enfermidades relacionadas a mutação de células e alteração das funções do organismo (SIES, 2013)

Substâncias antioxidantes são fundamentais para combater os radicais livres, ou seja, elas perdem elétrons e continuam com estabilidade. Estas substâncias compreendem vitaminas, minerais, compostos provenientes de material vegetal (LAYALI et al. 2015). Os antioxidantes por serem fundamental para saúde humana, são amplamente estudados e frequentemente localizados em fontes vegetais (KRISHNAIAH; SARBATLY; NITHYANANDAM, 2011).

Um dos métodos usados para identificar a capacidade antioxidante de um determinado material é pelo método DPPH (2,2-difenil- 1-picril- hidrazil) (Figura 2), no qual se caracteriza com um radical livre estável em virtude da deslocalização do elétron sobre a molécula. Quando o material em análise possui algum caráter antioxidante ele reage com o DPPH, originando a forma reduzida do reagente (DPPH-H). A redução provoca a alteração de sua coloração passando da cor violeta para amarelada (MOLYNEUX et al., 2004).

A planta Morinda citrifolia Linn. originária do sudeste da Ásia e difundida no mundo inteiro é conhecida 


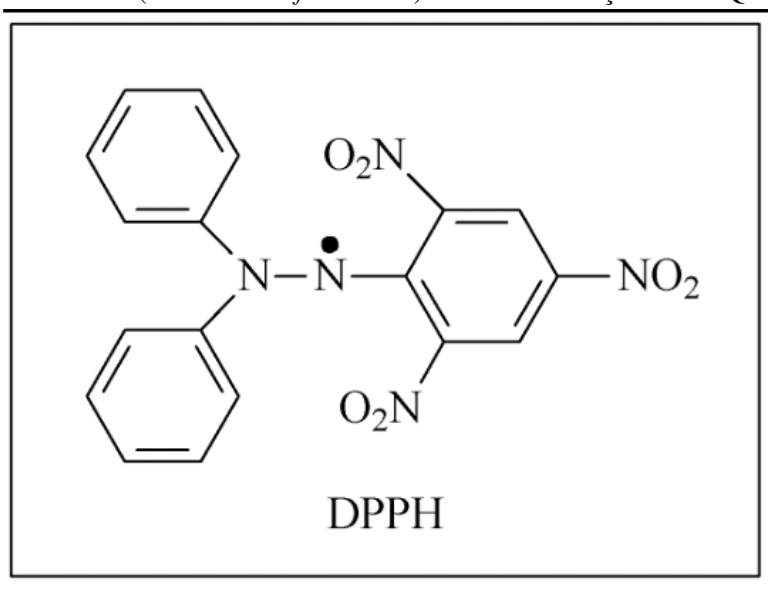

Figura 2: Estrutura química do DPPH (2,2-difenil-1-picril-hidrazil).

popularmente por noni, pertencente à família das Rubiaceae. No conhecimento empírico, as partes da planta: fruto, flor, caule, folhas e raiz possuem a capacidade de evitar e combater diversas doenças, tais como: câncer, artrite, diabetes, hipertensão, dentre outras (BASAR et al., 2010; BROWN, 2012).

Os frutos da planta quando maduros apresentam coloração que varia de esbranquiçado para amarelado, possuindo a polpa carnosa e suculenta de odor e sabor característico, possuindo em seu interior uma grande quantidade de sementes. Quando a planta começa a dar frutos ela produz o ano inteiro (WANG et al., 2002). As folhas têm formato elíptico com coloração verde intenso na parte superior e verde opaco na parte inferior. As flores são pequenas de coloração branca (MCCLATCHEY, 2002).

Muitos compostos fitoquímicos foram identificados em diversas partes da planta, dando destaque a compostos fenólicos, ácidos orgânicos e alcaloides (CHANBLANCO et al., 2006). Estes compostos estão relacionados a propriedades terapêuticas, possuindo papel importante na cura e prevenção de doenças.

A planta chegada ao Brasil foi disseminada, rapidamente em todas as regiões do país e as partes que a compõem são utilizadas em sucos, tratamento terapêutico, dentre outros. Para consumo humano são proibidas pela Agência Nacional de Vigilância Sanitária (ANVISA), por ainda não apresentar devida confirmação nutricional, científica e/ou farmacológica (ANVISA, 2007).

\section{Materiais e Métodos}

\section{Material vegetal}

Folhas e o fruto do noni pertencente à família Rubiaceae, foram coletadas do horto de plantas medicinais do Instituto Federal de Educação, Ciência e Tecnologia do Ceará - Campus Quixadá. A exsicata foi depositada no herbário da Universidade Federal do Ceará (UFC) - Campus Pici (Fortaleza - Ceará), com número de registro 54065.

\section{Extrato etanólico da folha de noni}

As folhas de noni foram lavadas e colocadas em estufa $\left(60^{\circ} \mathrm{C}\right)$ para secagem, logo após foram maceradas e armazenadas sem umidade até utilização.

Para preparar o extrato etanólico, as folhas do noni maceradas foram imersas em álcool etílico $(75 \%)$ na proporção 1:7 (g/mL) por um período de sete dias e deixadas à temperatura ambiente. A mistura resultante foi filtrada e colocada em banho maria $\left(85^{\circ} \mathrm{C}\right)$ para evaporação do solvente (Figura 3 ).

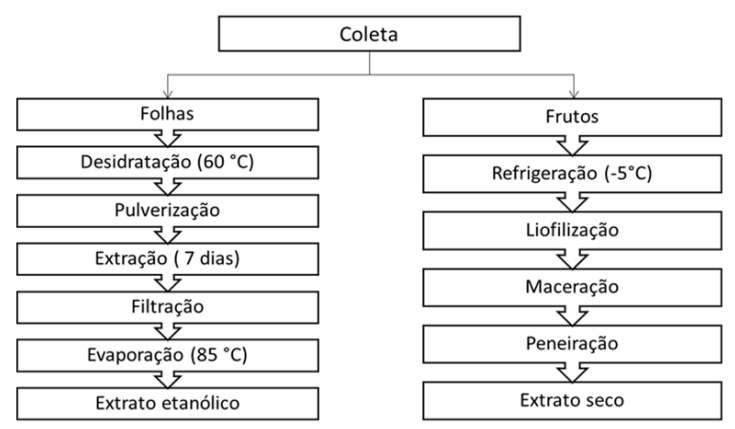

Figura 3: Fluxograma coleta material vegetal e preparo do extrato etanólico da folhas e extrato seco do fruto do noni.

\section{Extrato seco do fruto do noni}

Separou-se, manualmente a polpa, a semente e a casca do fruto maduro. Colocou-se cada parte do vegetal em recipientes distintos, em seguida, deixado sob refrigeração $\left(-5^{\circ} \mathrm{C}\right)$ até total congelamento. O material foi liofilizado, logo após macerado e peneirado para realizarem-se as análises (Figura 3).

\section{Análise fitoquímica da folha e do fruto do noni}

Realizaram-se ensaios fitoquímicos para identificação da presença de fenóis, taninos, antocianinas, antocianidinas, flavonóides, leucoantocianidinas, catequinas, flavonas e saponinas conforme metodologia adotada por Matos (2009). Preparou-se a solução mãe do extrato de cada parte da planta: folha, polpa, casca e semente. Pesou-se $10 \mathrm{~g}$ de extrato de cada parte e adicionou-se $70 \mathrm{~mL}$ de álcool (75\%), filtrou-se. A solução foi reservada para as análises. No teste de fenóis e taninos, colocou-se $1 \mathrm{~mL}$ de cada extrato em tubos 
de ensaio separados, logo após gotejou-se três gotas de solução alcoólica de $\mathrm{FeCl}_{3}$, agitou-se e anotou-se qualquer variação na coloração ou formação de precipitado. Para determinação de antocianinas, antocianidinas e flavonóides, colocou-se $1 \mathrm{~mL}$ do extrato em três tubos de ensaio distintos, em seguida, um extrato foi acidificado em $\mathrm{pH} 3$ e os outros dois alcalinizados um deles em $\mathrm{pH}$ 8,5 e outro em pH 11, então anotou-se a variação na tonalidade.

Enquanto, nas análises de leucoantocianidinas, catequinas e flavonas, separou-se dois tubos de ensaio e colocou $1 \mathrm{~mL}$ do extrato em cada um deles, logo em seguida, acidificou-se o primeiro com $\mathrm{HCl}(0,1 \mathrm{M})$ até pH 3 e alcalinizou-se o outro com $\mathrm{NaOH}(0,1 \mathrm{M})$ até pH 11, em seguida, aqueceu-se em lâmpada de álcool por 3 minutos. Anotou-se alteração para intensificação ou aparecimento de nova coloração em comparação ao teste anterior.

Já para determinação de saponinas, homogeneizouse $1 \mathrm{~g}$ do extrato em tubo de ensaio com $3 \mathrm{~mL}$ de água destilada por 3 minutos, anotou-se formação de espuma persistente.

\section{Determinação da atividade antioxidante, in vitro, do extrato da folha do noni, pelo método DPPH}

Preparou-se a solução padrão de 400 ppm do extrato da folha de noni e uma solução metanólica de DPPH de concentração $6,5 \times 10-5 \mathrm{~mol} / \mathrm{L}$. A partir desta solução, foram preparadas diluições em álcool metílico (PA) nas concentrações de 200, 260, 300, 320, 340, 360, 380 ppm. De cada uma dessas concentrações do extrato, transferiu-se uma alíquota de $0,1 \mathrm{~mL}$ e adicionou-se $3,9 \mathrm{~mL}$ da solução de DPPH, em seguida, agitou-se até completa homogeneização. Ao branco, adicionouse $0,1 \mathrm{~mL}$ de álcool metílico (PA) e $3,9 \mathrm{~mL}$ da solução de DPPH (Figura 4).

Os tubos de ensaio permaneceram ao abrigo da luz durante uma hora até estabilização seguindo a metodologia proposta por Silva et al. (2012), todas as leituras foram feitas em triplicata em espectrofotômetro a 515 nm. O procedimento foi realizado na ausência de luz. Após a leitura das absorbâncias, encontrou-se o índice de varredura (IV) de todas as leituras (Equação 1):

$$
I V=\left(\frac{A b s_{D P P H}-A b s_{a m o s t r a}}{A b s_{D P P H}}\right) \times 100
$$

Onde: $A b s_{D P P H}$ é a absorbância do DPPH; $A b s_{\text {Amostra }}$ é a absorbância das amostras em diferentes concentrações. Logo após, obtido IV de todas as absorbâncias em suas respectivas concentrações, realizou-se

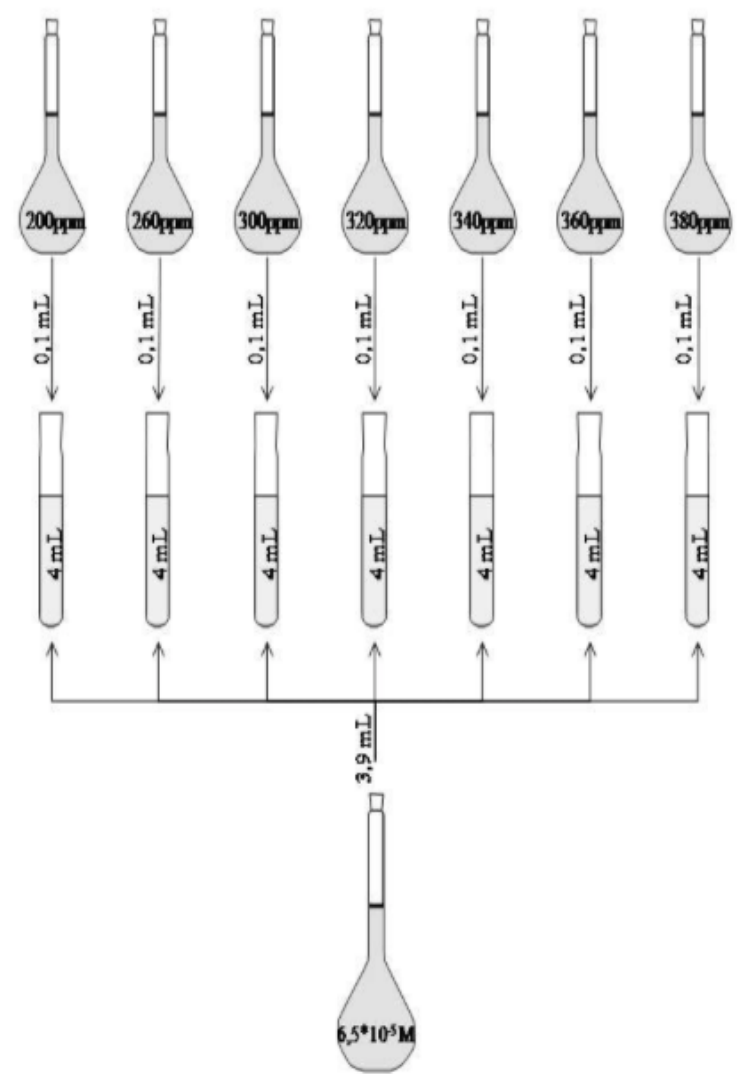

Figura 4: Fluxograma diluições DPPH e extratos da folha do noni. 
NONI (Morinda citrifolia Linn.): DETERMINAÇÃO FITOQUÍMICA E POTENCIAL ANTIOXIDANTE PELO MÉTODO DPPH

as médias. A concentração eficiente $\left(\mathrm{EC}_{50}\right)$, ou seja, a quantidade de antioxidante necessária para decrescer a concentração inicial de DPPH em $50 \%$. A equação da reta e a correlação linear $\left(\mathrm{R}_{2}\right)$ foram determinadas usando programa Microcal Origin 7.5, por meio de uma reta de regressão linear, obtida plotando-se no eixo das abscissas as concentrações (ppm) e na ordenada as médias do índice de varredura de cada concentração analisada. As médias, juntamente com seus respectivos desvios padrões, foram utilizadas para analisar os resultados, aplicando-se ANOVA para determinar as diferenças estatísticas de comparações múltiplas pelo teste de Tukey. O critério de significância $5 \%$ de probabilidade $(\mathrm{p}<0,05)$. As análises foram tratadas em software $M i$ crocal Origin 7.5.

\section{Resultados e Discussão}

\section{Análise fitoquímica do extrato da folha e fruto do noni}

$\mathrm{Na}$ determinação de fenóis e taninos, o extrato da folha apresentou coloração verde escuro, já os extratos da casca, polpa e semente exibiu tonalidade verde claro, assim como observado na Tabela 1 .

\begin{tabular}{cc} 
Tabela 1 - Determinação fenóis e taninos. \\
\hline \multicolumn{2}{c}{ Teste Fenóis e Taninos } \\
\hline Parte Analisada & Coloração \\
\hline Casca & Verde claro \\
Polpa & Verde claro \\
Folha & Verde escuro \\
Semente & Verde claro \\
\hline
\end{tabular}

$\mathrm{Na}$ avaliação de antocianinas, antocianidinas e flavonóides, observou-se a variação de coloração da folha, polpa e semente em mudanças de $\mathrm{pH}$. Porém, a casca apresentou tonalidade constante ao mesmo processo (Tabela 2).

\begin{tabular}{cccc}
\multicolumn{4}{c}{ Tabela 2 - Determinação de antocianinas, antocianidinas e flavonóides. } \\
\hline \multicolumn{4}{c}{ Teste Antocianinas, Antocianidinas e Flavonóides } \\
\hline Parte Analisada & pH 3 & pH 8,5 & pH 11 \\
\hline Folha & Verde escuro & Amarelo & Amarelo \\
Polpa & Amarelo alaranjado & Amarelo & Amarelo \\
Semente & Amarelo alaranjado & Amarela esverdeada & Amarela esverdeada \\
Casca & Amarelo & Amarelo & Amarelo \\
\hline
\end{tabular}

No teste para qualificação de leucoantocianidinas, catequinas e flavonas, notou-se variação de tonalidade nos extratos da polpa e semente, já a coloração dos extratos da casca e folha não se obteve variação quando submetidos a alteração de pH (Tabela 3).

\begin{tabular}{ccc}
\multicolumn{3}{c}{ Tabela 3 - Determinação leucoantocianidinas, catequinas e flavonas. } \\
\hline \multicolumn{3}{c}{ Teste Leucoantocianidinas, Catequinas e Flavonas } \\
\hline Parte Analisada & pH 3 & pH 11 \\
\hline Polpa & Laranja-vermelhado & Amarelo \\
Semente & Amarelo palha & Verde claro \\
Casca & Amarelo palha & Amarelo palha \\
Folha & Verde escuro & Verde escuro \\
\hline
\end{tabular}

No teste, saponinas todos os extratos apresentaram formação de espuma persistente, estando presente heterosídeos saponínicos. Na Tabela 4, abaixo, observase os resultados positivos para metabólitos secundários existentes nos extratos analisados.

$\begin{gathered}\text { Tabela 4 } \\
\text { - Resultado da análise fitoquímica da folha e fruto do noni. } \\
\text { [resultado positivo (+), resultado negativo (-)] }\end{gathered}$
\begin{tabular}{lcccc}
\multicolumn{5}{c}{ TRIAGEM FITOQUÍMICA } \\
\hline Composto Químico & \multicolumn{5}{c}{ Extrato Etanólico } \\
\hline & Folha & Polpa & Casca & Semente \\
\hline Catequinas & - & - & + & + \\
Flavonas & + & + & + & + \\
Flavonóis & + & + & + & + \\
Leucoantocianidinas & - & + & - & - \\
Saponinas & + & + & + & + \\
Taninos Flobabênicos & + & + & + & + \\
Xantonas & + & + & + & + \\
\hline
\end{tabular}

Faria et al. (2014), ao realizarem o estudo fitoquímico do fruto verde e maduro do noni, a partir do extrato hidroalcóolico, identificaram a presença taninos, flavonóides, antraquinonas conjugadas, saponinas, cumarinas e alcalóides. Lima e Lima (2013), ao analisar os metabólitos secundários presentes no extrato etanólico do fruto maduro e verde do noni identificou a presença de alcalóides, glicosídeos cardiotônicos, cumarinas voláteis, flavonóides, taninos e triterpenos.

Oliveira et al. (2013), ao analisar o extrato etanólico do fruto e folhado noni determinou a existência de taninos, triterpenos e saponinas. Nayak, Sandiford e Maxwell (2009) determinaram a presença de fenóis, alcalóides, esteróis, triterpenos e ácidos carboxílicos em extrato etanólico da folha do noni. Muitos compostos encontrados por esses autores, também foram encontrados nesse estudo, confirmando os resultados científicos obtidos.

A variação fitoquímica de uma mesma espécie analisada poder ser justificada por meio das partes estudadas, bem como dependente do local que o material vegetal é cultivado (CHAN-BLANCO et al., 2006. DENG; WEST; JENSEN, 2010).

Nota-se que, os diversos constituintes encontrados 
na literatura apresentaram resultados positivos para alguns metabólitos testados neste trabalho, a divergência dos resultados obtidos pode ser justificada pela diferente metodologia adotada pelo pesquisador.

\section{Atividade antioxidante do extrato da folha de noni}

O extrato etanólico da folha foi utilizado para avaliar a atividade antioxidante pelo método de DPPH. A figura 5 apresenta o cálculo das médias índice de varredura $X$ concentração (ppm), em que, se obteve a equação da reta: $y=0,0117 x+0,0825$. A partir desta equação, pode-se encontrar o $\mathrm{EC}_{50}=4,27 \pm 0,004 \mathrm{~g} / \mathrm{L}$, já a correlação linear $\mathrm{R}^{2}=0,99543$ representa a linearidade da reta. $\mathrm{O} \mathrm{R}^{2}$ mostra que a reta teve linearidade de $99,54 \%$. A capacidade antioxidante do extrato etanólico da folha de noni pode estar relacionada à presença de flavonóides presentes no extrato, como comprovado na prospecção fitoquímica.

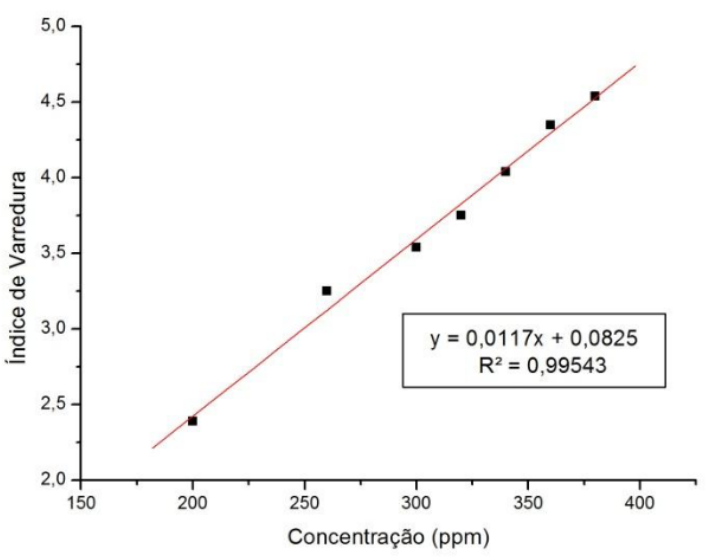

Figura 5: Reta de regressão linear da ação antioxidante do extrato etanólico da folha de noni.

Sousa et al. (2007), ao estabelecerem um padrão de comparação utilizou ácido gálico, no qual obtevese $\mathrm{EC}_{50}=0,02427 \pm 0,00031 \mathrm{~g} / \mathrm{L}$. Para comparação dos demais resultados obtidos. Soares et al. (2013), analisaram o extrato aquoso do fruto de noni e Cruz (2012), o extrato etanólico da folha em concentrações baixas, através da metodologia da captura de radicais livres DPPH, onde ambos obtiveram cerca de $85 \%$ da captura de radicais sob concentração de $0,1 \mathrm{~g} / \mathrm{L}$. Mota et al. (2012) avaliaram a atividade antioxidante das folhas de noni, pelo método do DPPH em extrato aquoso, conseguindo $E C_{50}=0,80854 \pm 0,00824 \mathrm{~g} / \mathrm{L}$. Mororó et al. (2015) realizaram testes antioxidantes com reagente DPPH utilizando extrato etanólico da folha de noni sob altas e baixas concentrações identificou eficácia antioxi- dante do extrato, devido a alteração na coloração. Sies e Stahl (1995) relatam que um bom antioxidante é caracterizado pela capacidade de capturar radicais livres mesmo em baixas concentrações.

Observando a diferença entre os resultados encontrados na presente pesquisa e os encontrados na literatura, pode ser explicado pela mudança de solvente, equipamento, e/ou concentração dos reagentes.

\section{Conclusão}

Constatou-se que a folha e o fruto do noni apresentaram uma diversidade de constituintes fitoquímicos, como: catequinas, flavonas, flavonóis, leucoantocianidinas, saponinas, taninos flabobênicos e xantonas. Já, a folha de noni apresentou uma possível ação antioxidante, sendo capaz de capturar radicais livres.

Sugere-se que a folha e o fruto sejam eficazes para o desenvolvimento de setores alimentícios e farmacêuticos, pois apresentam constituintes fitoquímicos e antioxidantes capazes de combater e prevenir enfermidades, assim como na conservação e proteção de alimentos quando isolados e aplicados adequadamente, todavia, necessita-se de estudos relacionados aos mecanismos de ação dos princípios ativos para ampla aplicação na farmacologia.

\section{REFERÊNCIAS}

ALMASSY JÚNIOR, A.; LOPES, R. C.; ARMOND, C.; SILVA, F.; CASALI, V. W. D. Folhas de chá: plantas medicinais na terapêutica humana. Viçosa: $U F V$, p. 233, 2005.

ANVISA. Esclarecimentos sobre as avaliações de segurança realizadas de produtos contendo Morinda cintrifolia, também conhecida como Noni. 2007.

AVELLO, M.; CISTERNAS, I. Fitoterapia, sus orígenes, características y situación en chile. Revista médica de Chile, SciELO Chile, v. 138, n. 10, p. 1288-1293, 2010.

BASAR, S.; UHLENHUT, K.; HÖGGER, P.; SCHÖNE, F.; WESTENDORF, J. Analgesic and antiinflammatory activity of morinda citrifolia l.(noni) fruit. Phytotherapy Research, Wiley Online Library, v. 24, n. 1, p. 38-42, 2010.

BOHLMANN, J.; KEELING, C. I. Terpenoid biomaterials. In: . : Wiley Online Library, 2008. v. 54, n. 4 , p. 656-669. 
NONI (Morinda citrifolia Linn.): DETERMINAÇÃO FITOQUÍMICA E POTENCIAL ANTIOXIDANTE PELO MÉTODO DPPH

BROWN, A. C. Anticancer activity of morinda citrifolia (noni) fruit: a review. Phytotherapy Research, Wiley Online Library, v. 26, n. 10, p. 1427-1440, 2012.

CHAN-BLANCO, Y.; VAILLANT, F.; PEREZ, A. M.; REYNES, M.; BRILLOUET, J.-M.; BRAT, P. The noni fruit (morinda citrifolia 1.): A review of agricultural research, nutritional and therapeutic properties. Journal of Food Composition and Analysis, Elsevier, v. 19, n. 6, p. 645-654, 2006.

CRUZ, M. F. Potencial antioxidante do extrato etílico da folha do noni (morinda citrifolia 1.). In: VII CONNEPI-Congresso Norte Nordeste de Pesquisa e Inovação. 2012.

DENG, S.; WEST, B. J.; JENSEN, C. J. A quantitative comparison of phytochemical components in global noni fruits and their commercial products. In: . : Elsevier, 2010. v. 122, n. 1, p. 267-270.

FARIA, W. C. S.; BETT, S. C.; SANTOS, C. G. B. dos; BRASIL, A. S.; GAUTO, R. F.; SELHORST, A. M.; BESERRA, S.; OLIVEIRA, A. P. de. Caracterização físico-química e análise fitoquímica preliminar do fruto noni (morinda citrofolia 1.) produzido na cidade de cuiabá-mt. Revista Brasileira de Tecnologia Agroindustrial, v. 8, n. 1, 2014.

HARBORNE, J. B. The flavonoids: advances in research since 1980. : Springer, 2013.

JONES, D. P. Radical-free biology of oxidative stress. American Journal of Physiology-Cell Physiology, Am Physiological Soc, v. 295, n. 4, p. C849-C868, 2008.

KRISHNAIAH, D.; SARBATLY, R.; NITHYANANDAM, R. A review of the antioxidant potential of medicinal plant species. Food and bioproducts processing, Elsevier, v. 89, n. 3, p. 217-233, 2011.

\section{LAYALI, I.; TAHMASBPOUR, E.; JOULAEI,} M.; JORSARAEI, S. G. A.; FARZANEGI, P. Total antioxidant capacity and lipid peroxidation in semen of patient with hyperviscosity. Cell Journal (Yakhteh), Royan Institute, v. 16, n. 4, p. 554, 2015.

LIMA, C. R. de; LIMA, R. A. Identificação de metabólitos secundários presentes no extrato etanólico dos frutos verdes e maduros de morinda citrifolia 1. Saúde e Pesquisa, v. 6, n. 3, p. 439-446, 2013.

MATOS, F. d. A. Introdução à fitoquímica experimental. : edições UFC, 2009.
MCCLATCHEY, W. From polynesian healers to health food stores: changing perspectives of morinda citrifolia (rubiaceae). Integrative cancer therapies, Sage Publications Sage CA: Thousand Oaks, CA, v. 1, n. 2, p. 110-120, 2002.

MOLYNEUX, P. et al. The use of the stable free radical diphenylpicrylhydrazyl (dpph) for estimating antioxidant activity. Songklanakarin J. Sci. Technol, v. 26, n. 2, p. 211-219, 2004.

MORORÓ, A. V. T. P.; ARAÚJO, N. P.; BEZERRA, S. B.; JÚNIOR, F. E. A. C.; SIQUEIRA, R. M. P. Análise da potencial atividade antioxidante in vitro do extrato etanólico das folhas de morinda citrifolia (noni) através do teste captura de radical livre dpph. In: Mostra de Produção Científica. Ceará: INTA, 2015. p. 24.

MOTA, M. D.; GUEDES, A. S.; SILVA, L. C. R. C.; LOPES, M. V.; SOUZA, M. P. C.; BARROS, W. M.

E. B. Triagem fitoquímica e potencial antioxidante da espécie morinda citrifolia 1. In: Simpósio de Plantas Medicinais do Brasil. Rio Grande do Sul: UFRGS, 2012.

NAYAK, B. S.; SANDIFORD, S.; MAXWELL, A. Evaluation of the wound-healing activity of ethanolic extract of morinda citrifolia 1. leaf. Evidence-Based Complementary and Alternative Medicine, Hindawi Publishing Corporation, v. 6, n. 3, p. 351-356, 2009.

OLIVEIRA, D. M. C. d. et al. Triagem de cinco espécies de plantas medicinais usadas na Amazônia através da análise de secreção de histamina. Tese (Doutorado) — Universidade Federal do Pará, Belém, 2013.

PELLETIER, S. W. Alkaloids: chemical and biological perspectives. : Springer, 1999. v. 13.

SIES, H. Hydroperoxides and thiol oxidants in the study of oxidative stress in intact cells and organs. Oxidative stress, Elsevier, Florida, p. 73-90, 2013.

SIES, H.; STAHL, W. Vitamins e and c, beta-carotene, and other carotenoids as antioxidants. The American journal of clinical nutrition, Am Soc Nutrition, v. 62, n. 6, p. 1315S-1321S, 1995.

SILVA, A. R. A. D.; MORAIS, S. M. de; MARQUES, M. M. M.; OLIVEIRA, D. F. de; BARROS, C. C.; ALMEIDA, R. R. D.; VIEIRA, Í. G. P.; GUEDES, M. I. F. Chemical composition, antioxidant and 
antibacterial activities of two spondias species from northeastern brazil. Pharmaceutical biology, Taylor \& Francis, v. 50, n. 6, p. 740-746, 2012.

SOARES, F. F. S.; CRUZ, M. F.; SOUZA, V. S. B.; LIMA, R. A. C.; SILVA, A. J.; JUNIOR, A. A. S. Análise do efeito antioxidante do extrato aquoso do noni (morinda citrifolia 1.). In: IX Congresso de Iniciação Científica do IFRN. 2013.

SOUSA, C. M.; SILVA, H. R.; VIEIRA-JR, G. M.; AYRES, M. C. C.; COSTA, C.; ARAÚJO, D. S.; CAVALCANTE, L. C. D.; BARROS, E. D. S.;

ARAÚJO, P. M.; BRANDÃO, M. S. et al. Fenóis totais e atividade antioxidante de cinco plantas medicinais. Química nova, São Paulo, v. 30, n. 2, p. 351-355, 2007.

SULTANA, B.; ANWAR, F. Flavonols (kaempeferol, quercetin, myricetin) contents of selected fruits, vegetables and medicinal plants. Food Chemistry, Elsevier, v. 108, n. 3, p. 879-884, 2008.

WAGNER, H.; HIKINO, H.; FARNSWORTH, N. R. Economic and medicinal plant research. : Academic press, 2012.

WALLER, G. Alkaloid biology and metabolism in plants. : Springer Science \& Business Media, 2012.

WANG, M.-Y.; WEST, B. J.; JENSEN, C. J.;

NOWICKI, D.; SU, C.; PALU, A. K.; ANDERSON, G. Morinda citrifolia (noni): a literature review and recent advances in noni research. Acta Pharmacologica Sinica, SCIENCE PRESS BEIJUNG, v. 23, n. 12, p. 1127-1141, 2002. 